\title{
Uncertainty Estimate of Surface Irradiances Computed with MODIS-, CALIPSO-, and CloudSat-Derived Cloud and Aerosol Properties
}

\author{
Seiji Kato • Norman G. Loeb • David A. Rutan • Fred G. Rose • \\ Sunny Sun-Mack $\cdot$ Walter F. Miller $\cdot$ Yan Chen
}

Received: 9 June 2011/Accepted: 20 January 2012/Published online: 23 February 2012

(C) The Author(s) 2012. This article is published with open access at Springerlink.com

\begin{abstract}
Differences of modeled surface upward and downward longwave and shortwave irradiances are calculated using modeled irradiance computed with active sensor-derived and passive sensor-derived cloud and aerosol properties. The irradiance differences are calculated for various temporal and spatial scales, monthly gridded, monthly zonal, monthly global, and annual global. Using the irradiance differences, the uncertainty of surface irradiances is estimated. The uncertainty $(1 \sigma)$ of the annual global surface downward longwave and shortwave is, respectively, $7 \mathrm{~W} \mathrm{~m}^{-2}$ (out of $345 \mathrm{~W} \mathrm{~m}^{-2}$ ) and $4 \mathrm{~W} \mathrm{~m}^{-2}$ (out of $192 \mathrm{~W} \mathrm{~m}^{-2}$ ), after known bias errors are removed. Similarly, the uncertainty of the annual global surface upward longwave and shortwave is, respectively, $3 \mathrm{~W} \mathrm{~m}^{-2}$ (out of $398 \mathrm{~W} \mathrm{~m}^{-2}$ ) and $3 \mathrm{~W} \mathrm{~m}^{-2}$ (out of $23 \mathrm{~W} \mathrm{~m}^{-2}$ ). The uncertainty is for modeled irradiances computed using cloud properties derived from imagers on a sun-synchronous orbit that covers the globe every day (e.g., moderate-resolution imaging spectrometer) or modeled irradiances computed for nadir view only active sensors on a sun-synchronous orbit such as Cloud-Aerosol Lidar and Infrared Pathfinder Satellite Observation and CloudSat. If we assume that longwave and shortwave uncertainties are independent of each other, but up- and downward components are correlated with each other, the uncertainty in global annual mean net surface irradiance is $12 \mathrm{~W} \mathrm{~m}^{-2}$. One-sigma uncertainty bounds of the satellite-based net surface irradiance are $106 \mathrm{~W} \mathrm{~m}^{-2}$ and $130 \mathrm{~W} \mathrm{~m}^{-2}$.
\end{abstract}

Keywords Surface net irradiance S Surface radiative energy budget

\section{Introduction}

Estimating the surface irradiance is important in understanding the energy cycle of the globe for several reasons. The sum of surface net irradiance and other surface enthalpy

S. Kato $(\bowtie) \cdot$ N. G. Loeb

Climate Science Branch, NASA Langley Research Center, Hampton, VA 23681-2199, USA

e-mail: seiji.kato@nasa.gov

D. A. Rutan - F. G. Rose - S. Sun-Mack - W. F. Miller · Y. Chen

Science System \& Applications Inc, Hampton, VA, USA 
(sensible and latent heat) fluxes is the energy flux through the lower boundary of the atmospheric column and the upper boundary of an ocean column. Therefore, the global mean net surface irradiance balances with the sum of the surface latent and sensible heat fluxes and ocean heating rate (Wong et al. 2006). In addition, the radiative net energy deposition in the atmosphere and vertical and horizontal profiles of the energy deposition determine the dynamics in the atmosphere. Understanding the top-of-atmosphere (TOA) surface and atmospheric irradiances quantitatively is, therefore, necessary to quantitatively understand the dynamics, which in turn controls cloud feedback processes (Wielicki et al. 1995). The global mean surface irradiance estimate is only possible through modeling surface irradiances. In earlier studies, cloud properties derived from passive satellite instruments combined with radiative transfer models have been used to estimate surface irradiance (e.g., Pinker and Laszlo 1992; Zhang et al. 1995, and a summary is given by Kandel and Viollier 2010).

While surface irradiances computed with satellite-derived and modeled cloud properties have been compared in earlier studies (e.g., Hatzianastassiou et al. 2005; Su et al. 2008; Stephens 2011), the uncertainty of surface irradiances averaged over different temporal and spatial scales, such as monthly or annual, and regional, zonal, or global, is not well understood. The purpose of this paper is to extend the study by Kato et al. (2011) to estimate uncertainties of surface irradiance components in various spatial and temporal scales $\left(1^{\circ} \times 30^{\circ}\right.$ or $1^{\circ} \times 1^{\circ}$ gridded, $1^{\circ}$ zonal, and global spatial scales and monthly and annual temporal scales).

In this study, we define the uncertainty as a range of surface irradiances in which the true value resides at a $68 \%$ probability. Our goal is different from estimating the error of a specific surface irradiance estimate, although we need to have a specific surface irradiance estimate to attach the uncertainty. Taylor and Kuyatt (1994) describe the difference nicely; the result of a measurement (modeled irradiance) could have a negligible error because it can unknowably be very close to the truth even though it may have a large uncertainty. There are two possible ways of estimating the modeled surface irradiance uncertainty. One way is to estimate the uncertainty of the input variables, perturb inputs by the uncertainty amount, and compute the irradiance using a radiative transfer model. The irradiance change by the sensitivity study is considered as the uncertainty due to input variables. Some earlier studies (e.g., Zhang et al. 1995; Zhang et al. 2004; Kim and Ramanathan 2008) used this approach. A second approach is to use surface observations and compute the root mean square (RMS) difference of modeled and observed surface irradiances. We primarily take the former approach in this study, but briefly examine how uncertainties derived by the two approaches differ.

Sections 2 and 3 present a brief overview of surface longwave and shortwave irradiance estimates, respectively, to understand the range of the global annual mean values. Section 4 briefly discusses the computation method using CALIPSO (Winker et al. 2010), CloudSat (Stephens et al. 2008), moderate resolution imaging spectrometer (MODIS) and Clouds and the Earth's Radiant Energy System (CERES) data. Section 5 analyzes the uncertainty of surface irradiances for various temporal and spatial scales by comparing two modeled irradiances (sensitivity approach). Section 6 uses surface observations to estimate modeled surface irradiance uncertainties (surface observation approach). Section 7 combines uncertainties of all surface irradiance components and discusses the uncertainty in the global annual net surface irradiance. 


\section{Global Annual Mean Surface Downward Longwave Irradiance}

Stephens et al. (2011) provide a summary of the global annual mean surface longwave upward and downward irradiance estimated from satellite observations, reanalysis, and ground-based observations. The global annual mean downward longwave irradiance estimated from satellite observations (GEWEX SRB, ISCCP-FD, CERES) ranges from 342 to $348 \mathrm{~W} \mathrm{~m}^{-2}$ (Stephens et al. 2011). The global annual mean downward longwave irradiance estimated by reanalyses ranges from 324 to $340 \mathrm{~W} \mathrm{~m}^{-2}$ (Stephens et al. 2011).

Wild et al. (2001) compared the global annual mean surface downward longwave irradiance computed in general circulation models (GCMs) with surface observations in Global Energy Balance Archive (GEBA) and Baseline Surface Radiation Network (BSRN, Ohmura et al. 1998) data sets. Their results show that the modeled global annual mean surface downward longwave irradiance by GCMs varies more than $40 \mathrm{~W} \mathrm{~m}^{-2}$, ranging from 303 to $344 \mathrm{~W} \mathrm{~m}^{-2}$. GCM-derived surface downward longwave irradiances are less than observed irradiances especially under dry and cold conditions. Their results suggest that the difference is caused by the underestimation of surface downward longwave irradiances under cloud-free conditions.

The global annual mean surface downward longwave irradiance under clear-sky conditions computed with satellite-based observations (passive sensor-derived clouds) and that from reanalyses shown in Stephens (2011) range from 309 to $326 \mathrm{~W} \mathrm{~m}^{-2}$, which is a smaller variation than all-sky values $\left(324-348 \mathrm{~W} \mathrm{~m}^{-2}\right.$ ). In addition, among values given by Stephens (2011), all but two clear-sky values agree to within a few $\mathrm{W} \mathrm{m}^{-2}$. All-sky global annual mean surface downward longwave irradiances from reanalyses tend to be smaller than satellite-based estimates (Stephens 2011), indicating that the difference is caused by clouds, especially low-level clouds. This suggests that cloud properties used in reanalyses are different from those derived from satellites and that the cloud difference is a source of the difference between satellite-based and reanalysis-based estimates for all-sky conditions.

When the global annual mean surface downward longwave irradiance is estimated using MODIS-derived cloud properties by the Ed2 CERES cloud algorithm (Minnis et al. 2011), the global annual mean value is smaller by $3.6 \mathrm{~W} \mathrm{~m}^{-2}$ compared with the irradiance estimated using CALIPSO and CloudSat-derived cloud properties (Kato et al. 2011). The exact value of the surface downward longwave irradiance difference caused by passive and active sensor-derived clouds depends on the cloud base height estimated from passive sensors. For example, the increase of the global mean surface downward longwave irradiance estimated by Zhang et al. (2004) using climatological cloud vertical profiles (Wang et al. 2000) from International Satellite Cloud Climatology Project C1 input data (ISCCPFC) is $1.8 \mathrm{~W} \mathrm{~m}^{-2}$.

Though these differences due to cloud base are significant, studies using satellitederived cloud properties by Zhang et al. (2006) and by Kato et al. (2011) show that the largest uncertainty in computing the global annual mean surface downward longwave irradiance is caused by uncertainty in near-surface air temperature and precipitable water. The uncertainty in the global annual mean surface downward longwave irradiance caused by surface temperature and water vapor amount estimated by Kato et al. (2011) is \pm 4.5 and $\pm 5.2 \mathrm{~W} \mathrm{~m}^{-2}$, respectively. Both are larger than the uncertainty due to cloud base height found in Kato et al. (2011). 


\section{Global Annual Mean Surface Shortwave Irradiance}

Comparisons of surface shortwave irradiances from previous studies are more problematic due to different assumptions made regarding TOA solar insolation. To avoid the effect of the insolation difference in various estimates, we use the surface absorptance, which is the net surface shortwave irradiance (downward minus upward) divided by the TOA insolation, to compare surface shortwave irradiances from earlier studies. The global annual mean surface absorptance ranges from 0.471 to 0.548 (Table 1). The absorptance given by L'Ecuyer et al. (2008) is the first estimate of the global annual mean surface downward shortwave irradiance using CloudSat-derived cloud properties. However, it is probably biased high because clouds that were undetected by CloudSat are missing in their computations. If we exclude the maximum and minimum values shown in Table 1, the absorptances range from 0.471 to 0.495 . This corresponds to a range of $8.2 \mathrm{~W} \mathrm{~m}^{-2}$, using an insolation of $341.3 \mathrm{~W} \mathrm{~m}^{-2}$.

Uncertainty in the surface downward shortwave irradiance is due to uncertainties in column water vapor amount, cloud and aerosol properties and their vertical profiles, treatment of diurnal cycle of clouds, the surface albedo, and the insolation. Based on a sensitivity study done by Zhang et al. (1995), if all surface downward shortwave irradiance changes considered in their study (atmospheric, surface, and cloud properties) are independent random errors with unknown sign, the uncertainty in the global annual mean irradiance is $15.3 \mathrm{~W} \mathrm{~m}^{-2}$ [out of $193.4 \mathrm{~W} \mathrm{~m}^{-2}$ (Rossow et al. 1995), based on an average from April 1985 through January 1989 using every third month]. Rossow (1995) also compared modeled surface downward shortwave irradiances with surface observations. The bias and RMS differences are from 10 to $20 \mathrm{~W} \mathrm{~m}^{-2}$ and from 10 to $15 \mathrm{~W} \mathrm{~m}^{-2}$, respectively. These values are consistent with modeled and observed surface downward shortwave irradiance difference given by Kato et al. (2008) at three Atmospheric Radiation Measurement (ARM) sites, $20.5 \mathrm{~W} \mathrm{~m}^{-2}$ for Manus, $12.6 \mathrm{~W} \mathrm{~m}^{-2}$ for Southern Great Plains (SGP), and $6.4 \mathrm{~W} \mathrm{~m}^{-2}$ for Barrow, Alaska.

There are also uncertainties in the observations of irradiance at the Earth's surface due to instrumentation. As pointed out by Gulbrandsen (1978), if the temperature gradient within the instrument is not corrected, surface downward shortwave irradiances measured by pyranometers can be biased low. Once the temperature gradient within a pyranometer is eliminated (e.g., Haeffelin et al. 2001), modeled clear-sky surface downward shortwave

Table 1 Global annual mean surface shortwave irradiance estimates

\begin{tabular}{llllll}
\hline & $\begin{array}{l}\text { SW down } \\
\left(\mathrm{W} \mathrm{m}^{-2}\right)\end{array}$ & $\begin{array}{l}\mathrm{SW} \mathrm{up} \\
\left(\mathrm{W} \mathrm{m}^{-2}\right)\end{array}$ & $\begin{array}{l}\mathrm{NET} \\
\left(\mathrm{W} \mathrm{m}^{-2}\right)\end{array}$ & $\begin{array}{l}\text { TOA insolation } \\
\left(\mathrm{W} \mathrm{m}^{-2}\right)\end{array}$ & $\begin{array}{l}\text { Surface } \\
\text { absorptance }\end{array}$ \\
\hline Gupta et al. (1999) & 185 & 24 & 161 & 341.3 & 0.472 \\
Zhang et al. (2004) & 189 & 24 & 165 & 341.8 & 0.483 \\
Hatzianastassiou et al. (2005) & 172 & 23 & 149 & 341.8 & 0.436 \\
Kim and Ramanathan (2008) & & & 164 & 348.1 & 0.471 \\
L'Ecuyer (2008) & 218 & 25 & 193 & 352 & 0.548 \\
Wang and Pinker (2009) & & & 168 & 341.7 & 0.492 \\
Trenberth et al. (2009) & 184 & 23 & 161 & 341.3 & 0.472 \\
Kato et al. (2011) & 192 & 23 & 169 & 341.3 & 0.495 \\
\hline
\end{tabular}

\footnotetext{
${ }^{\text {a }}$ Only area covered by the CloudSat ground track and $82^{\circ} \mathrm{N}$ to $82^{\circ} \mathrm{S}$ is considered
} 
irradiances agree with observations to within 1\% (Michalsky et al. 2006) when accurate temperature and humidity profiles, aerosol properties, and surface albedo are used.

\section{Top-of-Atmosphere (TOA) and Surface Radiative Flux Estimate Using CALIPSO- and CloudSat-Derived Clouds}

Active instruments can detect clouds better than passive sensors. Active instruments can also observe cloud base heights, while the cloud base height derived from passive sensors relies on climatological vertical cloud profiles (Zhang et al. 2004) or an empirical relationship based on the cloud physical thickness, cloud top temperature, and optical thickness (Minnis et al. 2010, 2011). Properly determining the cloud base height improves the accuracy of the surface downward longwave irradiance. In addition, active sensors can detect multi-layer clouds and can improve cloud detections, particularly at nighttime over the polar regions. Furthermore, better cloud top height derived from CALIPSO and CloudSat leads to a better estimate of the emission component in near-infrared channels, which can improve MODIS-derived cloud properties (Kato et al. 2011).

Improvements in modeled TOA and surface irradiances using Cloud-Aerosol Lidar with Orthogonal Polarization (CALIOP)- and CloudSat Cloud Profiling Radar (CPR)-derived cloud and aerosol properties compared with irradiances computed with MODIS only are investigated by Kato et al. (2011) using 1 year of CALIPSO, CloudSat, CERES, and MODIS combined data. When 1 year of TOA instantaneous irradiances computed with CALIOP- and CPR-derived properties are averaged globally, the reflected shortwave irradiance decreases by $12.5 \mathrm{~W} \mathrm{~m}^{-2}(5.0 \%$, relative to MODIS only) and the longwave irradiance increases by $2.5 \mathrm{~W} \mathrm{~m}^{-2}(1.1 \%$, relative to MODIS only). As a consequence, both the reflected shortwave and longwave irradiances computed with CALIOP- and CPRderived properties agree better with CERES-derived TOA irradiances to within $0.5 \mathrm{~W} \mathrm{~m}^{-2}$ (out of $237.8 \mathrm{~W} \mathrm{~m}^{-2}$ CERES value) for reflected shortwave and $2.6 \mathrm{~W} \mathrm{~m}^{-2}$ (out of $240.1 \mathrm{~W} \mathrm{~m}^{-2}$ CERES value) for longwave irradiances. Differences in monthly zonal mean irradiance are, however, larger at some latitudes than the difference of the global mean irradiances. Therefore, a good agreement with the global annual mean CERES-derived irradiance is, in part, because of compensating errors. Nevertheless, the result of Kato et al. (2011) indicates that the accuracy of modeled global annual mean irradiances improves when CALIOP- and CPR-derived cloud and aerosol properties are used. A summary of surface irradiances estimated by Kato et al. (2011) is shown in Table 2. Note that a bias of $1.5 \mathrm{~W} \mathrm{~m}^{-2}$ in the surface downward longwave irradiance, which is explained in Sect. 5 and in Kato et al. (2011), is expressed explicitly in Table 2.

\section{Uncertainty Estimates}

In this section, we calculate the longwave and shortwave surface upward and downward irradiances using two different methods and assume the difference between these methods defines the irradiance uncertainty primarily due to cloud input differences. In computations with CALIPSO and CloudSat, the B1 enhanced algorithm (Minnis 2010) is used to derive cloud properties from MODIS radiances. In computations with MODIS only, the Ed2 CERES cloud algorithm (Minnis 2011) is used to derive cloud properties from MODIS radiances. Cloud properties derived from MODIS are used in both cases, but in the first (B1 enhanced), the passive retrieval is enhanced by the addition of the cloud information 
Table 2 Global annual mean surface irradiance estimated by Kato et al. (2011)

\begin{tabular}{ll}
\hline & Irradiance $\left(\mathrm{W} \mathrm{m}^{-2}\right)$ \\
\hline Longwave down & $345.4+1.5$ \\
Longwave up & 398.1 \\
Shortwave down & 191.9 \\
Shortwave up & 22.8
\end{tabular}

supplied by CALIPSO and CloudSat, whereas in the second (Ed2), the passive retrieval stands alone. Aerosol optical thicknesses are given by the MODIS level 2 aerosol product, MYD04 (Remer et al. 2005), in both computations. CALIPSO provides the height of aerosol layers for computations with CALIPSO and CloudSat data. Aerosol type determines optical properties of aerosol for shortwave and longwave computations. When CALIPSO detects dust layers, dust aerosols are used in irradiance computations, while the aerosol type in the MODIS only irradiance computations relies on an aerosol transport model. Ocean surface albedos are from Jin et al. (2004) with slightly different foam parameters in computations with MODIS only and with CALIPSO and CloudSat. Broadband land surface albedos are inferred from MODIS narrowband albedos (Moody et al. 2005) for computations with CALIPSO and CloudSat data. MODIS only computations use the clear-sky TOA albedo derived from CERES measurements (Rutan et al. 2009).

Figures 1 and 2 show, respectively, the surface downward longwave irradiance difference and the relative difference of the surface downward shortwave irradiance. We calculate the RMS difference of these two sets of irradiances averaged over four different temporal and spatial scales, gridded, $1^{\circ}$ zonal, and global spatial scales and monthly and annual temporal scales. We use a $30^{\circ}$ longitude $\times 1^{\circ}$ latitude grid box because this assures at least one sample a day in a grid box by CALIPSO and CloudSat. CALIPSO and CloudSat provide better cloud properties, but do not cover the entire grid box every day as does MODIS. The assumption is that the RMS difference represents the irradiance bounds in which the true gridded monthly mean irradiance computed with perfect cloud and aerosol properties resides at a $68 \%$ probability. We expect a similar uncertainty in the modeled irradiance computed for a $1^{\circ} \times 1^{\circ}$ degree grid box with full swath data because most grid boxes are sampled daily. The RMS differences of two sets of irradiances are used to estimate the uncertainties. For example, the RMS difference of gridded monthly mean irradiances is computed to estimate the gridded irradiance uncertainty. Similarly, the RMS of $1^{\circ}$ zonal monthly mean irradiances is computed to estimate the monthly zonal irradiance uncertainty. Estimated uncertainties are summarized in Table 3. Uncertainty estimates are given for ocean and land separately because of the significant differences in clouds and atmospheric properties over each surface type. Their combined uncertainty is, at times, smaller than ocean or land alone due to a partial cancelation of errors when irradiances over both surface types are averaged over a $1^{\circ}$ zone. The uncertainty of the monthly gridded value is the average of ocean and land values weighted by, respectively, 0.7 and 0.3 , instead of using ocean and land-mixed grid box values. Uncertainty in the surface upward irradiance over polar regions can be very large because identifying the presence of snow and ice is sometimes difficult. For this reason, the uncertainty of regional surface upward shortwave irradiance does not apply over the polar regions.

Uncertainty in the surface upward longwave irradiances is due primarily to uncertainty in the skin temperature. Both modeled irradiances with and without active sensors share the 

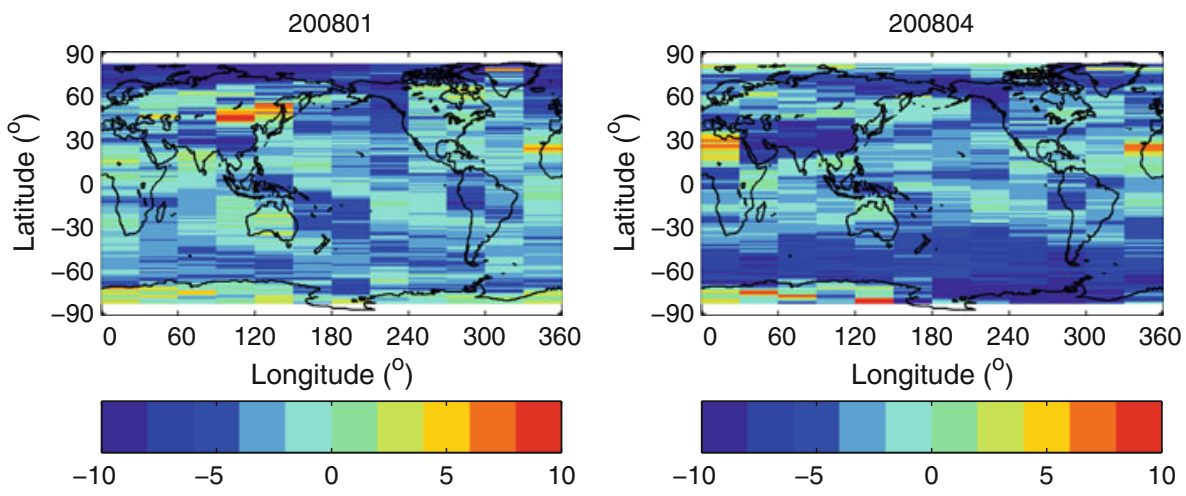

200807
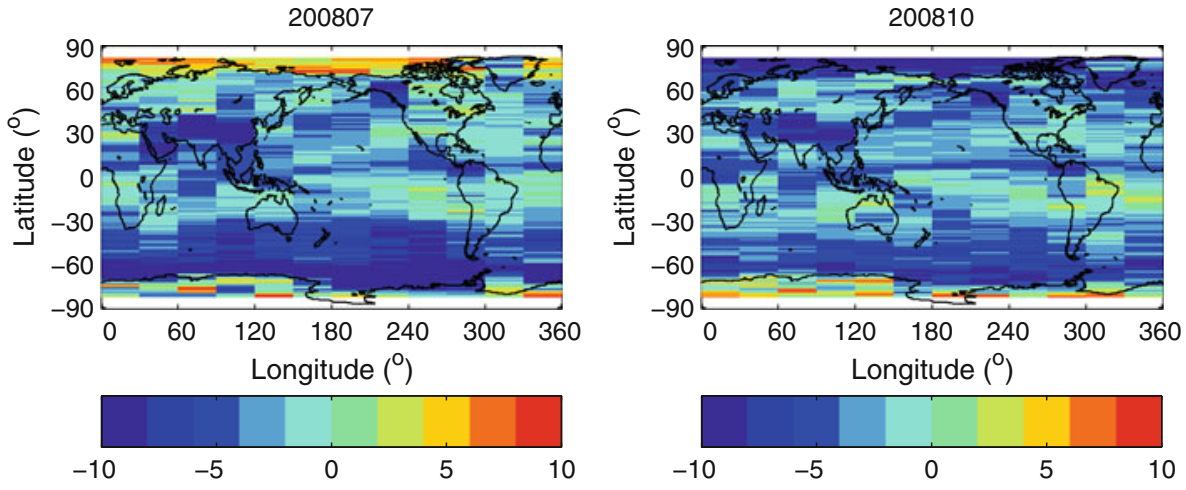

Fig. 1 Monthly mean surface longwave downward irradiance difference gridded in $1^{\circ}$ latitude by $30^{\circ}$ longitude grids. The difference is defined as the irradiance computed with MODIS only minus the irradiance computed with CALIPSO and CloudSat

same Goddard Earth Observing System (GEOS-5)-derived, (Rienecker et al. 2008; Bloom et al. 2005) surface skin temperature as an input. Instead of using the irradiance RMS difference, therefore, we compute the RMS skin temperature difference between that extracted from GEOS-5 and the skin temperature derived from MODIS when the MODIS, CALIPSO, and CloudSat data all indicate the scene is clear. This allows us to estimate the uncertainty in the upward longwave irradiance using the RMS surface skin temperature difference and the mean surface skin temperature.

Because the level 2 footprint products we used in this study do not account for the diurnal cycle of insolation, the RMS difference of shortwave irradiances is computed as the relative difference from the mean value. We then multiply the relative RMS difference by the mean irradiance estimated with diurnal cycle of insolation [values extracted from the CERES AVG product (Kato et al. 2011)]. For example, the surface downward shortwave uncertainty is computed by multiplying the mean of relative RMS differences shown in Fig. 2 by a mean irradiance accounting for a diurnal cycle shown in Table 3 .

Uncertainties caused by aerosol optical properties and precipitable water in the surface downward shortwave irradiance are not included in the difference between active sensorand passive sensor-derived surface downward shortwave irradiances described above. According to Kim and Ramanathan (2008), uncertainty in the global annual mean net surface shortwave irradiance under clear-sky conditions due to aerosol optical thickness, 

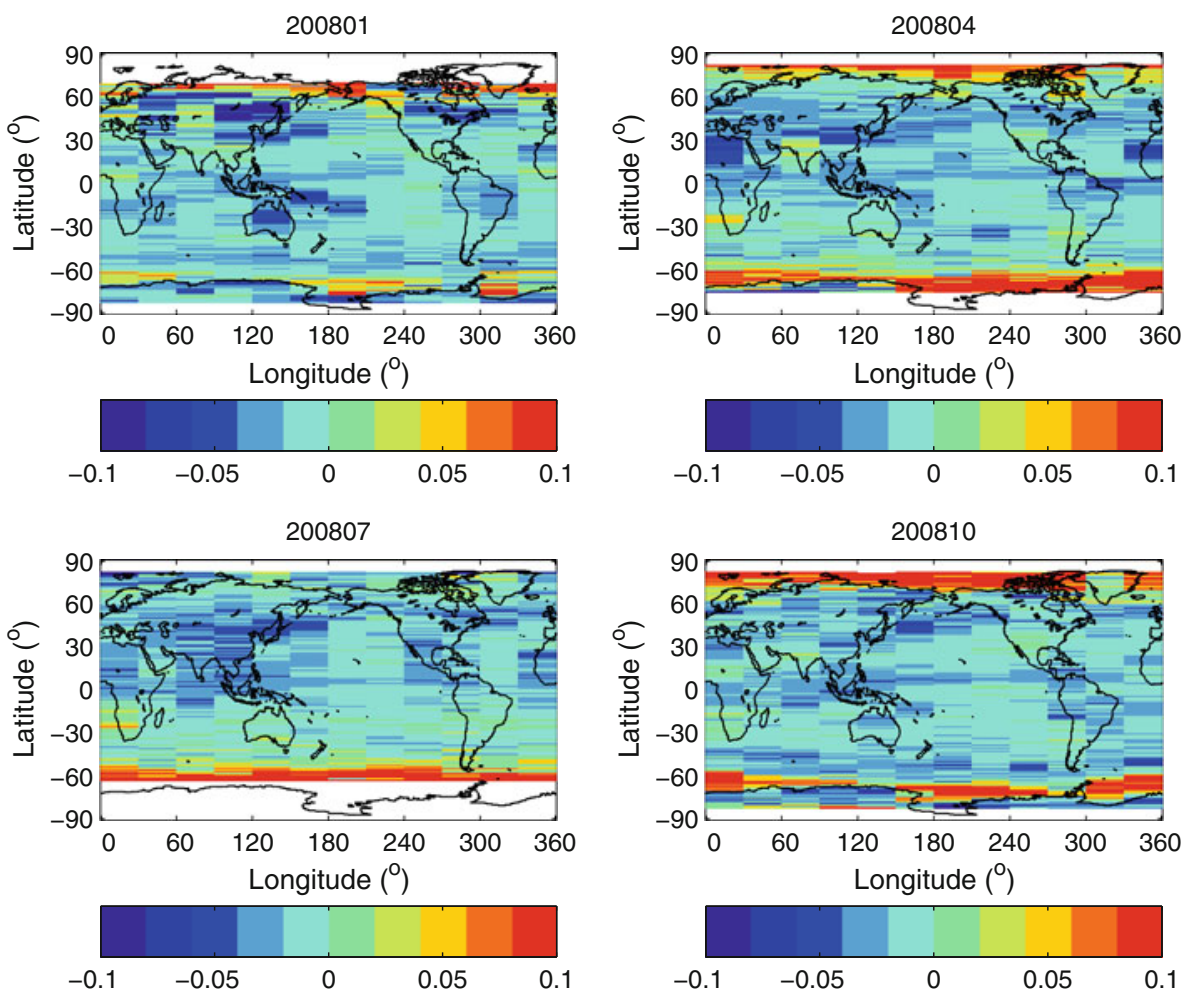

Fig. 2 Monthly mean surface shortwave downward irradiance relative difference gridded in $1^{\circ}$ latitude by $30^{\circ}$ longitude grids. The relative difference is defined as the irradiance computed with MODIS only minus the irradiance computed with CALIPSO and CloudSat divided by the irradiance computed with CALIPSO and CloudSat

single scattering albedo, precipitable water, and ozone amount is, respectively, $1.5 \mathrm{~W} \mathrm{~m}^{-2}$, $1.5 \mathrm{~W} \mathrm{~m}^{-2}, 1.3 \mathrm{~W} \mathrm{~m}^{-2}$, and $0.4 \mathrm{~W} \mathrm{~m}^{-2}$. If these uncertainties are independent, the sum of these uncertainties leads to a $2.9 \mathrm{~W} \mathrm{~m}^{-2}, 2.7 \mathrm{~W} \mathrm{~m}^{-2}, 3.4 \mathrm{~W} \mathrm{~m}^{-2}$ uncertainty in the global annual mean net surface shortwave irradiance for land plus ocean, ocean, and land, respectively, after converting the net uncertainty to the downward irradiance uncertainty using corresponding global annual mean surface albedos. Considering that these uncertainties are in addition to that derived from irradiance differences primarily due to clouds, we take the square root of the sum of squares of the value and the RMS difference due to clouds for the global annual mean surface downward shortwave uncertainty. For all other temporal- and spatial-scale uncertainties listed in Table 3, we simply add the value to the RMS difference due to clouds. Table 4 summarizes input variables considered in estimating the uncertainties.

Table 3 shows that the uncertainty in different temporal and spatial scales differs. When the error in passive sensor-derived cloud properties depends on cloud type and the probability distribution of cloud type occurrence changes month to month, the irradiance uncertainty computed with them is relatively large. However, even though a particular cloud type occurs in a grid box, the probability distribution of cloud type tends to be constant when the probability is computed over a larger area and a longer time period. If 
Table 3 Summary of uncertainties in the irradiance computed with satellite-derived cloud and aerosol properties, in $\mathrm{Wm}^{-2}$

\begin{tabular}{lllllll}
\hline & Mean value & \multicolumn{2}{l}{ Estimated uncertainty } & & \\
\cline { 5 - 7 } & & & $\begin{array}{l}\text { Monthly } \\
\text { gridded }\end{array}$ & $\begin{array}{l}\text { Monthly } \\
\text { zonal }\end{array}$ & $\begin{array}{l}\text { Monthly } \\
\text { global }\end{array}$ & $\begin{array}{l}\text { Annual } \\
\text { global }\end{array}$ \\
\hline \multirow{2}{*}{ Downward longwave } & Ocean + land & 345 & 14 & 11 & 7 & 7 \\
& Ocean & 354 & 12 & 10 & 7 & 7 \\
& Land & 329 & 17 & 15 & 8 & 7 \\
Upward longwave & Ocean + Land & 398 & 15 & 8 & 3 & 3 \\
& Ocean & 402 & 13 & 9 & 5 & 5 \\
Downward shortwave & Land & 394 & 19 & 15 & 5 & 4 \\
& Ocean + Land & 192 & 10 & 8 & 6 & 4 \\
& Ocean & 190 & 9 & 8 & 5 & 4 \\
Upward shortwave & Land & 203 & 12 & 10 & 7 & 5 \\
& Ocean + Land & 23 & 11 & 3 & 3 & 3 \\
& Ocean & 12 & 11 & 3 & 3 & 3 \\
& Land & 53 & 12 & 8 & 6 & 6 \\
\hline
\end{tabular}

the magnitude of the error decreases by shifting a cloud type distribution with a specific cloud type preferentially occurring in the distribution to a uniform distribution among all cloud types, the bias error tends to cancel. Because the cloud distribution tends to be uniform and stable with time, if we use larger spatial and longer temporal scales, the uncertainty decreases at increasing temporal and spatial scales.

The discussion of how the bias error with known sign is separated from the uncertainty follows, using the uncertainty estimates given in Kato et al. (2011). The cloud base height detected by CloudSat can cause a $1.1 \mathrm{~W} \mathrm{~m}^{-2}$ bias error in the global annual mean downward longwave irradiance due to precipitation. If three-hourly skin temperature and one-hourly temperature and humidity profiles are used as opposed to one-hourly skin temperature and temperature and humidity profiles, then the global annual mean surface downward irradiance decreases by $2.6 \mathrm{~W} \mathrm{~m}^{-2}$ due to missing peak values during daytime (Kato et al. 2011). The uncertainty in irradiance caused by the uncertainty in the nearsurface temperature and precipitable water is $\pm 6.9 \mathrm{~W} \mathrm{~m}^{-2}$. Based on this, the range of the global annual mean surface downward longwave irradiance computed with CALIPSO- and CloudSat-derived cloud and aerosol properties is from -5.4 to $8.4 \mathrm{~W} \mathrm{~m}^{-2}(+2.6-$ $1.1 \pm 6.9 \mathrm{~W} \mathrm{~m}^{-2}$ ). If the global annual mean surface downward longwave irradiance is estimated using only MODIS-derived cloud and aerosol properties, bias errors of cloud fraction and cloud base height cause $\mathrm{a}-3.4 \mathrm{~W} \mathrm{~m}^{-2}$ irradiance bias (Kato et al. 2011). This leads to the range of the passive sensor-derived global annual mean surface downward longwave irradiance of $-0.2-14.0 \mathrm{~W} \mathrm{~m}^{-2}\left(+2.6+3.4-1.1 \pm 6.9 \mathrm{~W} \mathrm{~m}^{-2}\right)$. If we treat these bounds as one standard deviation (i.e., 2 out of 3 chance that the modeled irradiance lies in the interval), then the uncertainty expressed is $6.9 \mathrm{~W} \mathrm{~m}^{-2}$ (the mean of the upper and lower bound) for both irradiances (Taylor and Kuyatt 1994). Note that bias error does not contribute to the uncertainty expressed in this way. The range where the true value resides for a specific irradiance estimate is computed by adding bias errors of the specific estimate to the uncertainty. Therefore, uncertainties shown in Table 3 are considered as values after known biases have been removed. The overall uncertainty in Table 4, 
Table 4 Uncertainty in the global annual mean surface irradiances (Ocean + Land), in $\mathrm{Wm}^{-2}$

\begin{tabular}{|c|c|c|c|}
\hline & Bias error with known sign & Uncertainty & References \\
\hline \multicolumn{4}{|c|}{ Surface downward longwave irradiance } \\
\hline Clouds base height & $-1.1^{\mathrm{a}}$ & & Kato et al. (2011) \\
\hline Temporal interpolation & -2.6 & & Kato et al. (2011) \\
\hline Surface temperature & & 4.5 & Kato et al. (2011) \\
\hline Precipitable water & & 5.2 & $\begin{array}{l}\text { Zhang et al. (2006), } \\
\text { Kato et al. (2011) }\end{array}$ \\
\hline Interannual variability & & 0.8 & Kato et al. (2011) \\
\hline Overall uncertainty & & 6.9 & \\
\hline \multicolumn{4}{|c|}{ Surface upward longwave irradiance } \\
\hline Surface skin temperature & & 3.2 & This study \\
\hline Interannual variability & & 0.4 & This study \\
\hline Overall uncertainty & & 3.2 & \\
\hline \multicolumn{4}{|c|}{ Surface downward shortwave irradiance } \\
\hline Clouds & & 2.8 & This study \\
\hline Aerosol optical thickness ${ }^{\mathrm{b}}$ & & 1.7 & $\begin{array}{l}\text { Kim and Ramanathan } \\
\text { (2008) }\end{array}$ \\
\hline $\begin{array}{l}\text { Aerosol single scattering } \\
\text { albedo }^{\mathrm{b}}\end{array}$ & & 1.7 & $\begin{array}{l}\text { Kim and Ramanathan } \\
\text { (2008) }\end{array}$ \\
\hline Precipitable water ${ }^{\mathrm{b}}$ & & 1.5 & $\begin{array}{l}\text { Kim and Ramanathan } \\
\text { (2008) }\end{array}$ \\
\hline Ozone $^{\mathrm{b}}$ & & 0.5 & $\begin{array}{l}\text { Kim and Ramanathan } \\
\text { (2008) }\end{array}$ \\
\hline Interannual variability & & 0.3 & This study \\
\hline Overall uncertainty & & 4.0 & \\
\hline \multicolumn{4}{|c|}{ Surface upward shortwave irradiance } \\
\hline Albedo & & 3.4 & This study \\
\hline Interannual variability & & 0.1 & This study \\
\hline Overall uncertainty & & 3.4 & \\
\hline
\end{tabular}

a $1.1 \mathrm{~W} \mathrm{~m}^{-2}$ is when active sensors are used but $-3.6 \mathrm{Wm}^{-2}$ when only passive sensor is used

b Surface albedo of 0.12 is used to estimate the downward shortwave uncertainty from the net shortwave uncertainty given by Kim and Ramanathan (2008)

therefore, does not include bias errors with known sign. One other factor that affects the uncertainty is the TOA irradiance derived from CERES observations. We assume that modeled surface irradiances are not independent of the TOA irradiance derived from CERES observations. In other words, modeled TOA irradiances need to be consistent with TOA CERES-derived irradiances to within their uncertainties.

\section{Comparison with Surface Observations}

Modeled and observed surface irradiances have been compared in many studies (e.g., Rossow and Zhang 1995; Rose et al. 2006; Charlock et al. 2006; Wang and Pinker 2009; Niu et al. 2010). The RMS difference between modeled and observed irradiances at surface sites can be used as a measure of uncertainty. The noise of temporal and spatial mismatch 
between observed surface irradiances, however, dominates especially shortwave irradiances in the comparisons. The uncertainty might be overestimated, if the surface site does not represent the grid box where the site is located when the RMS difference of modeled and observed surface irradiance is used as the uncertainty.

Figure 3 shows comparison of modeled monthly $1^{\circ} \times 1^{\circ}$ gridded surface longwave and shortwave downward irradiances with surface observations. Modeled irradiances are extracted from the edition 2 CERES AVG product. The 26 grid boxes used in the sample have surface observation sites located within their boundaries. Surface sites and grid boxes are selected such that surface properties in the vicinity of the site adequately represent the entire grid box ("Appendix"). For example, surface sites on islands or at high elevations with variable terrain are excluded. Surface observations are averaged over a month. Five years of data from March 2000 through February 2005 are used. The RMS difference for the surface downward longwave and shortwave irradiances is, respectively, 9.4 and $8.5 \mathrm{~W} \mathrm{~m}^{-2}$.

We can separate the RMS difference into three components,

$$
r^{2}=r_{s}^{2}+r_{t}^{2}+r_{m}^{2},
$$

where $r$ is the RMS difference computed with the difference between modeled gridded monthly mean irradiance and observed monthly mean irradiance, $r_{s}$ is the RMS difference due to variability of surface irradiance within the grid (spatial sampling), $r_{t}$ is the uncertainty due to temporal resolution of modeled irradiance, and $r_{m}$ is modeling error and the noise due to matching modeled irradiances with surface observations. The spatial RMS error $r_{s}$ arises because observations at a surface site measure the irradiance at one location while satellite observations cover the entire grid box. The temporal sampling based on satellite observation is typically limited to several times a day with a sun-synchronous orbit or once every $3 \mathrm{~h}$ or $1 \mathrm{~h}$ with a geostationary satellite. Modeling error includes the error in the inputs and assumptions in the model. In addition, the difference caused by matching instantaneous modeled irradiance with surface observations at satellite overpass time, as
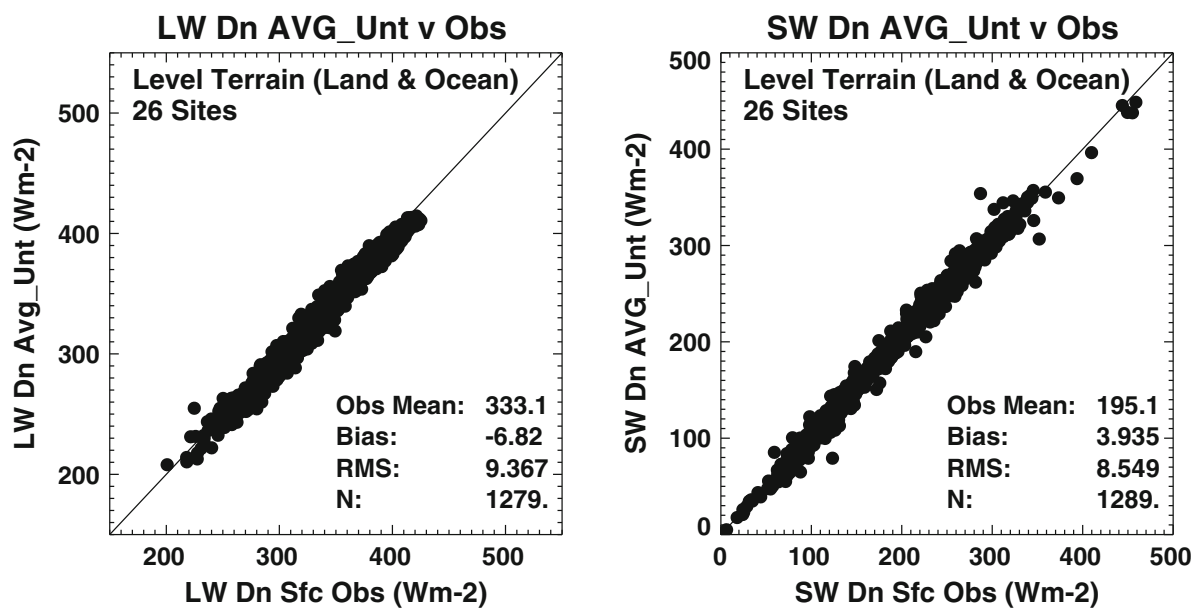

Fig. 3 Comparison of monthly mean observations at 26 surface sites and $1^{\circ} \times 1^{\circ}$ monthly mean modeled surface downward longwave irradiance (left) and surface downward shortwave irradiance (right). Modeled irradiances are extracted from Ed2 CERES AVG product. Data from March 2000 through October 2005 are used 
well as the uncertainty in surface observations are included in $r_{m}$ because the noise is not easily separated from the modeling error.

The RMS difference shown in Fig. 3 is the sum of these three components. When the surface properties at a surface observation site do not represent the surface property of the grid where the surface site is located, $r_{s}$ is large ("Appendix"). If surface sites indicated by green bars in Figs. 5 and 6 are used, however, $r_{s}$ is almost negligible for the monthly mean surface downward longwave irradiance and $2.6 \mathrm{~W} \mathrm{~m}^{-2}$ for the monthly mean surface downward shortwave irradiance. Comparisons are made between instantaneous modeled irradiances and observed irradiances at the satellite overpass time, and scaling the instantaneous irradiance difference to the daily mean value gives the $r_{m}$ term. The temporal sampling term $r_{t}$ can be inferred from modeled and observed daily mean irradiance comparison, or if we assume the relationship given by Eq. 1, $r_{t}$ can also be derived from $r$, provided $r_{s}$ and $r_{m}$ are known. We estimate the three components from monthly mean modeled and observed irradiances comparisons at 26 sites where the surface sites represent the grid box surface properties relatively well (Table 5). The values of $r_{t}$ in Table 5 are derived from $r, r_{s}$, and $r_{m}$, which are the residual of the relationship given by Eq. 1 for the RMS difference and $r_{t}=r-r_{s}-r_{m}$ for the bias. The RMS differences might be considered as spatial sampling noise $r_{s}$, temporal sampling noise $r_{t}$, and instantaneous modeling error $r_{m}$ for a typical grid box. Note that a large downward shortwave irradiance $r_{t}$ bias is due to a larger $r_{m}$, which is a result of matching the TOA reflected shortwave irradiance with the CERES-derived reflected shortwave irradiance (Rose et al. 1997). The difference between modeled and CERES-derived TOA irradiances, therefore, affects the modeled surface irradiance.

The RMS difference shown in Fig. 3 is computed with monthly mean gridded and observed surface irradiances. In principle, if we have a surface site in a grid box, we can remove $r_{t}$ and $r_{m}$ by comparing gridded monthly mean modeled irradiance with surface observations. Then, the uncertainty of modeled surface irradiance is $r_{s}$ because the modeled irradiance cannot be evaluated better than the spatial sample noise. If we have at least one surface site in each grid box and ignore measurement uncertainty, then the uncertainty of modeled irradiance, in principle, can be much smaller and equal to $r_{s}$. Because most grid boxes do not have surface sites, the uncertainty of monthly gridded mean modeled irradiance is somewhat equivalent to the RMS difference shown in Fig. 3. Figure 4 shows a comparison of the RMS difference from Fig. 3 and the uncertainty of the gridded monthly mean surface downward longwave and shortwave irradiances from Table 3. Uncertainties of gridded monthly mean downward longwave and shortwave irradiances listed in Table 3

Table 5 Monthly gridded mean irradiance uncertainties derived from modeled and observed surface irradiances ${ }^{\mathrm{a}}$, in $\mathrm{Wm}^{-2}$

\begin{tabular}{lcclc}
\hline & Total $^{\mathrm{b}}, r$ & Spatial sampling, $r_{s}$ & Temporal sampling ${ }^{\mathrm{c}}, r_{t}$ & Modeling error, $r_{m}$ \\
\hline LW down RMS & 9.7 & 1.3 & 6.7 & 6.9 \\
SW down RMS & 8.4 & 4.1 & 2.7 & 6.8 \\
LW down mean bias & -7.0 & -0.1 & Negligible & -6.9 \\
SW down mean bias & 3.8 & -2.3 & -0.6 & 6.7 \\
\hline
\end{tabular}

\footnotetext{
${ }^{a}$ Derived from 26 surface sites used in Fig. 3

b Values derived from Fig. 3 scaled by 345 (from Table 3)/333 (mean LW observation value) and 192 (from Table 3)/195 (mean SW observation value)

c Values derived from, $r, r_{s}$, and $r_{m}$
} 

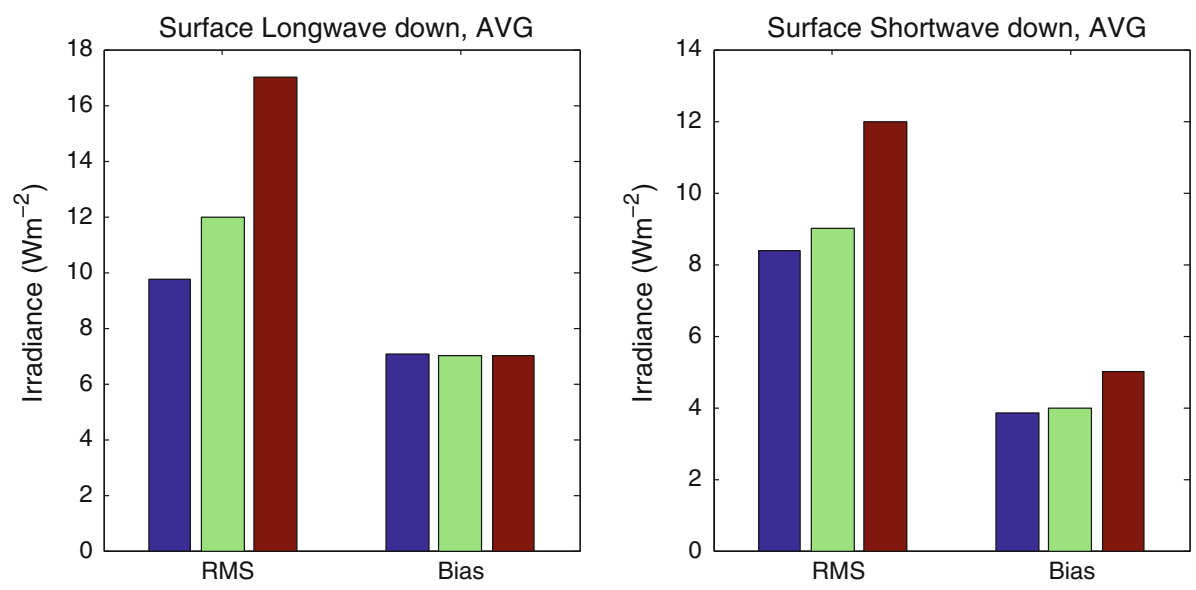

Fig. 4 (Left) Comparison of the root square mean (RMS) error (left blue bar) and bias error (right blue bar) derived from Fig. 3 with the uncertainty of the monthly gridded surface downward longwave irradiance over ocean (left green bar) and over land (left brown bar) and with the uncertainty annual global surface downward longwave irradiance over ocean (right green bar) and over land (right brown bar). The uncertainties are from Table 3. Right). Same as the left plot but for surface downward shortwave irradiance

are larger than the RMS difference. This indicates that our estimate is on the conservative side according to the comparison with surface observations.

The bias difference of monthly gridded mean irradiances and observations shown in Fig. 3 is not zero. This suggests that even when many modeled irradiances are averaged for large regions such as zonal or global or a longer time scale such as annual mean, the irradiance error does not completely cancel out. As a consequence, the global annual mean irradiance uncertainty might be comparable to the mean bias shown in Fig. 3. The comparison shown in Fig. 4 is consistent with this expectation.

\section{Discussion and Conclusions}

The uncertainty of the downward longwave irradiance is the largest uncertainty among the global annual mean surface irradiance component uncertainties (Table 3). The global annual mean surface downward longwave irradiance is $345.4 \mathrm{~W} \mathrm{~m}^{-2}$ with an estimated bias error of $-1.5 \mathrm{~W} \mathrm{~m}^{-2}$ (Kato et al. 2011). Therefore, the $1 \sigma$ range is 339.9-353.9 $\mathrm{W} \mathrm{m} \mathrm{m}^{-2}\left(345.4+1.5 \pm 7 \mathrm{~W} \mathrm{~m}^{-2}\right)$. The spread of the global annual mean surface downward longwave irradiance using satellite observations discussed in Sect. 2 is $6 \mathrm{~W} \mathrm{~m}^{-2}$ (342-348 $\mathrm{W} \mathrm{m}^{-2}$ ), which is smaller than the $7 \mathrm{~W} \mathrm{~m}^{-2}$ uncertainty estimated in this study.

The global annual mean surface downward shortwave irradiance estimated in Kato et al. (2011) is $191.9 \mathrm{~W} \mathrm{~m}^{-2}$. One- $\sigma$ bounds of the global annual mean downward shortwave irradiance are $187.9-195.9 \mathrm{~W} \mathrm{~m}^{-2}$ (with the insolation of $341.3 \mathrm{~W} \mathrm{~m}^{-2}$ ). The uncertainty of the global annual mean surface up and downward shortwave irradiances estimated in this study is, respectively, 3 and $4 \mathrm{~W} \mathrm{~m}^{-2}$. If we assume upward and downward shortwave irradiance uncertainties are correlated, the uncertainty of global annual mean net surface shortwave irradiance is $7 \mathrm{~W} \mathrm{~m}^{-2}$. One- $\sigma$ bounds of the global annual mean surface absorptance are $0.475-0.516$. The spread of the global annual mean surface net shortwave irradiance discussed in Sect. 3 is $8.2 \mathrm{~W} \mathrm{~m}^{-2}$ (the absorptance from 0.471 to 0.495 ), if we 
exclude the maximum and minimum values. The uncertainty estimated in this study is close to the spread of values estimated by earlier studies discussed in Sect. 3, but $50 \%$ (3 out of 6) of the values fall outside the one- $\sigma$ bounds.

Given the uncertainty in Table 3, it is possible to estimate the uncertainty in the global annual net surface irradiance. However, the uncertainties in the four irradiance components are not independent. For example, the surface temperature uncertainty affects both upward and downward longwave irradiances. Similarly, if surface downward shortwave irradiance is overestimated, then surface upward shortwave irradiance is probably overestimated. We therefore assume that the shortwave and longwave components are independent, but that upward and downward irradiance uncertainties are correlated. Adding upward and downward components, squaring the sum of shortwave and longwave components, summing them, and taking the square root of the resulting value gives an uncertainty of the global annual mean net surface irradiance of $12 \mathrm{~W} \mathrm{~m}^{-2}$. Therefore, $1 \sigma$ bounds of the global annual mean net surface irradiance are $117.9 \pm 12 \mathrm{~W} \mathrm{~m}^{-2}$ (from 105.9 to 129.9 $\mathrm{W} \mathrm{m}{ }^{-2}$ ). Note that the $-1.5 \mathrm{~W} \mathrm{~m}^{-2}$ bias error in the downward longwave irradiance (Kato et al. 2011) is subtracted from the mean value in this estimate.

Studies by Zhang et al. (2006) and Kato et al. (2011) indicate that when satellite-derived cloud and aerosol properties are used for computations, uncertainty in the surface downward longwave irradiance is dominated by the uncertainty in near surface temperature and precipitable water. Because the uncertainty in the surface downward longwave irradiance is the largest component of the uncertainty in the net surface irradiance, the improvement of near-surface temperature and precipitable water accuracy is necessary to improve the net surface irradiance estimate. The estimate of diurnal cycle of satellite-derived cloud properties relies on geostationary satellites, which provide less accurate cloud properties than MODIS. The process to incorporate geostationary satellite-derived cloud properties in the irradiance estimate minimizes the effect of the error in geostationary-derived cloud properties (Young et al. 1998). In addition, the diurnal cycle correction to the top-ofatmosphere global annual mean shortwave irradiance is small (Loeb et al. 2009). The uncertainty due to the error in the geostationary satellite-derived cloud properties is, however, not explicitly included in the current uncertainty estimate. Investigating the effect of geostationary-derived cloud properties on the surface downward shortwave irradiance is necessary to further understand the uncertainty in the surface net irradiance.

Acknowledgments We thank Drs. Graeme Stephens, Tristan L'Ecuyer, Martin Wild, Tom Charlock, and Tom Ackerman for useful discussions and two anonymous reviewers for providing constructive comments. We also thank Ms. Amber Richards for proof reading the manuscript. The work was supported by the NASA's CERES and NASA Energy and Water Cycle Study (NEWS) projects. CERES data are supplied by the NASA Langley Research Center Atmospheric Sciences Data Center. ARM data is made available through the U.S. Department of Energy as part of the Atmospheric Systems Research Program. NOAA SURFRAD (Augustine et al. 2000) and GMD data are made available through the NOAA's Earth System Research Laboratory/Global Monitoring Division - Radiation (G-RAD). The Woods Hole Oceanographic Institute, Upper Ocean Processes (UOP) group, supplies NTAS and STRATUS buoy data.

Open Access This article is distributed under the terms of the Creative Commons Attribution License which permits any use, distribution, and reproduction in any medium, provided the original author(s) and the source are credited.

\section{Appendix: Surface Observation Spatial Sampling Noise Estimate}

To understand the spatial sampling noise within a 1 degree grid box, we use two sets of modeled surface irradiances extracted from CERES products, CRS and SYN. CRS is a 
level 2 product that contains instantaneous modeled surface irradiances at the local Terra overpass time. SYN is a level 3 product that contains temporally averaged estimates of surface irradiance, where hourly modeled irradiances represent the entire $1^{\circ} \times 1^{\circ}$ grid box. We subset CRS irradiances within $25 \mathrm{~km}$ from surface sites and average them over a month. The resulting mean irradiance simulates surface observations at overpass time averaged over a month. We also subset SYN monthly mean irradiances from a subset of grid boxes that coincide with the Terra satellite overpass time. The 62 grid boxes were selected from a larger set used for CERES validation. Some contain surface observation sites and some simply represent ecosystems of interest. If the box contains a surface observation site, the $25-\mathrm{km}$-radius region from which CRS is averaged is centered at that site (though in this analysis no surface observations are used). If there is no surface site, then the CRS footprints fall within $25 \mathrm{~km}$ of the center of the $1^{\circ}$ grid box. We then

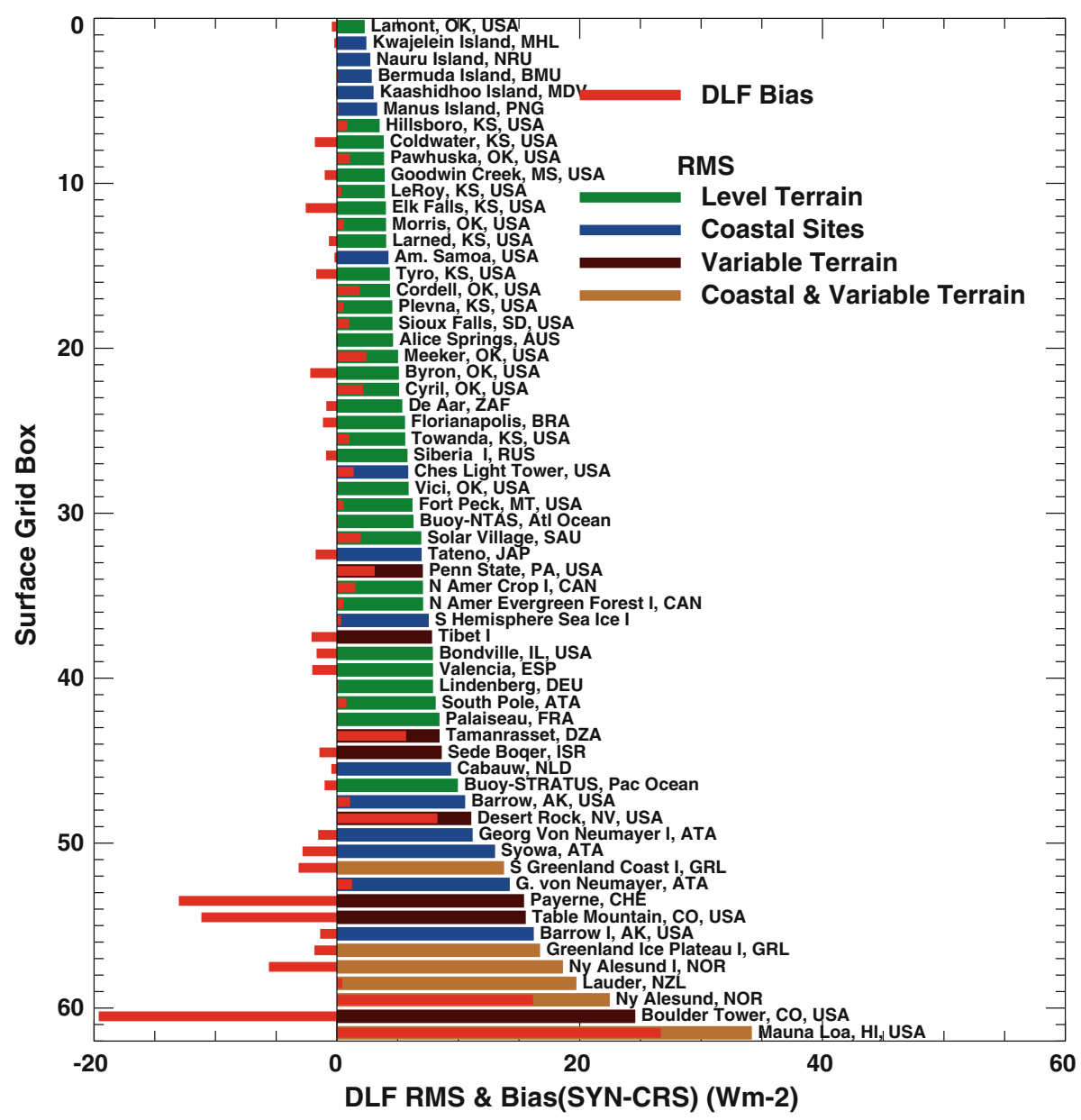

Fig. 5 Sampling noise estimate for 62 surface sites. The RMS difference and bias are estimated comparing modeled downward longwave irradiances at Terra local overpass time within $25 \mathrm{~km}$ from the surface location averaged over a month and $1^{\circ} \times 1^{\circ}$ gridded monthly mean irradiances within 30 min from overpass time (i.e., an hour box contains the local overpass time). Six Julys from 2000 through 2005 are used 


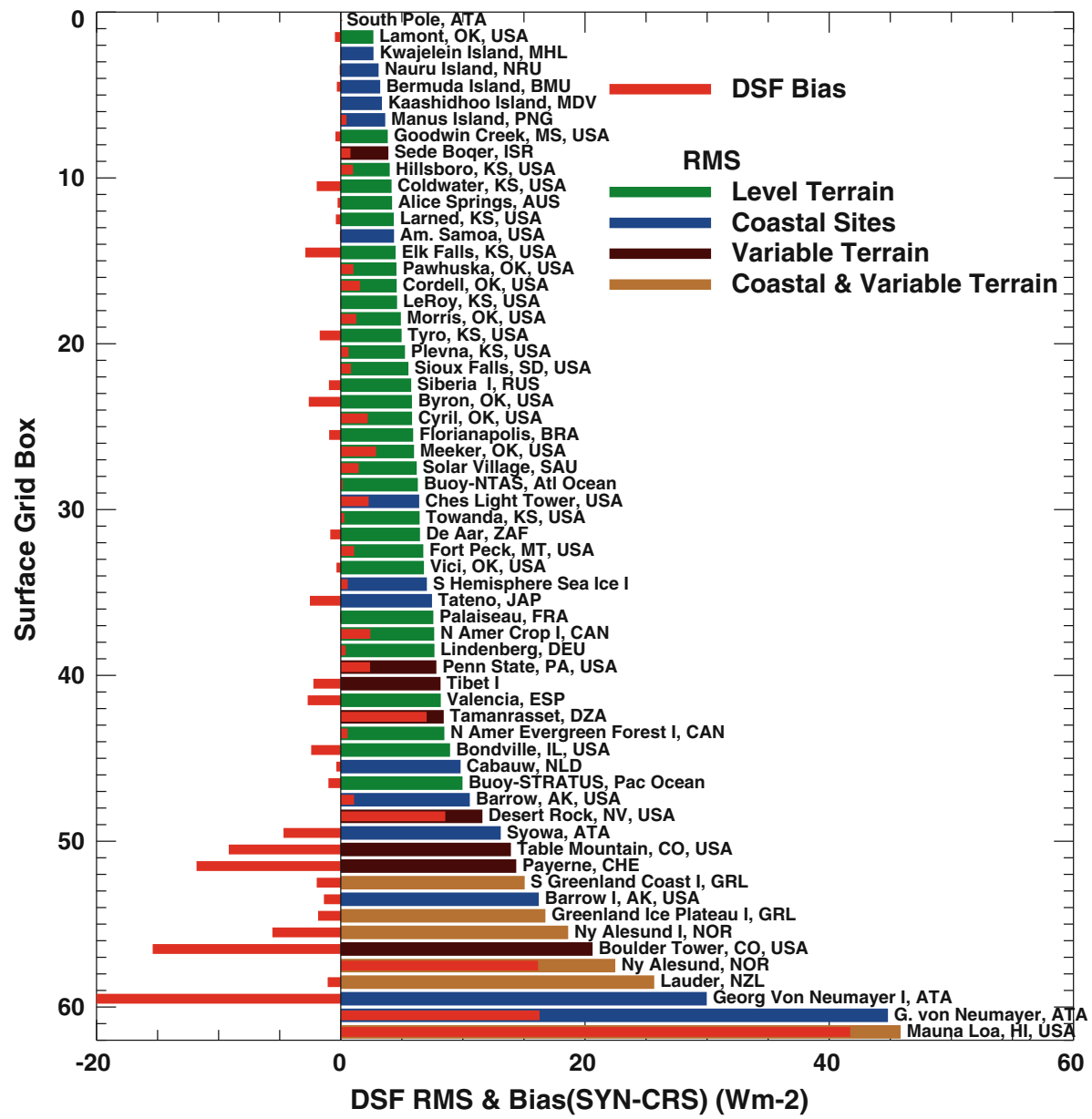

Fig. 6 Same as Fig. 5 but for the surface downward shortwave irradiance

compute the RMS difference between the CRS and SYN monthly means for each locations using 6 Julys (2000 through 2005). Figures 5 and 6 show the histogram of the RMS differences. Surface locations are separated into four different groups: uniform terrain, coastal, variable terrain, and coastal and variable terrain. The 26 sites used in Fig. 3 are a subset of those shown in Figs. 5 and 6 that contain surface observations and are designated as uniform terrain (Figs. 5, 6).

\section{References}

Augustine JA, DeLuisi JJ, Long CN (2000) SURFRAD-a national surface radiation budget network for atmospheric research. Bull Amer Met Soc 81(10):2341-2358

Bloom SA et al (2005) Documentation and validation of the Goddard Earth Observing System (GEOS) data assimilation system version-4, Technical Report Series on global modeling and data assimilation, 104606, 26

Charlock TP, Rose FG, Rutan DA, Jin Z, Kato S (2006) The global surface and atmosphere radiation budget: an assessment of accuracy with 5 years of calculations and observations. In: Proceedings of 12th 
conference on atmospheric radiation, 10-14, July, Madison Wisconsin. Available at http://snowdog. larc.nasa.gov/cave/

Gulbrandsen A (1978) On the use of pyranometers in the study of spectral solar radiation and atmospheric aerosols. J Appl Meteorol 17:899-904

Gupta SK, Ritchey NA, Wilber AC, Whitlock CH, Gibson GG, Stackhouse PW Jr (1999) A climatology of surface radiation budget derived from satellite data. J Clim 12:2691-2710

Haeffelin M, Kato S, Smith AM, Rutledge K, Charlock TP, Mahan JR (2001) Determination of the thermal offset of the Eppley precision spectral pyranometer. Appl Opt 40:472-484

Hatzianastassiou N, Matsoukas C, Fotiadi A, Pavlakis KG, Drakakis E, Hatzidmitriou D, Vardavas I (2005) Global distribution of Earth's surface shortwave radiation budget. Atmos Chem Phys 5:2847-2867

Jin Z, Charlock TP, Smith WL Jr, Rutledge K (2004) A look-up table for ocean surface albedo. Geophys Res Lett 31:L22301

Kandel R, Viollier M (2010) Observation of the Earth's radiation budget from space. C R Geosci 342:286-300. doi:10.1016/j.crte.2010.01.005

Kato SF, Rose G, Rutan DA, Charlock TP (2008) Cloud effects on the meridional atmospheric energy budget estimated from clouds and the Earth's radiant energy system (CERES) data. J Clim 4223-4241

Kato S, Rose FG, Sun-Mack S, Miller WF, Chen Y, Rutan DA, Stephens GL, Loeb NG, Minnis P, Wielicki BA, Winker DM, Charlock TP, Stackhouse PW, Xu K-M, Collins W (2011) Computation of top-ofatmosphere and surface irradiances with CALIPSO, CloudSat, and MODIS-derived cloud and aerosol properties. J Geophys Res 116:D19209. doi:10.1029/2011JD016050

Kim D, Ramanathan V (2008) Solar radiation budget and radiative forcing due to aerosols and clouds. J Geophys Res 113:D02203. doi:10.1029/2007JD008434

L'Ecuyer TS, Wood NB, Haladay T, Stephens GL, Stackhouse PW Jr (2008) Impact of clouds on atmospheric heating based on the R04 CloudSat fluxes and heating rate data set. J Geophys Res 113, D00A15, doi:10.1029/2008JD009951

Loeb GN, Wielicki BA, Doelling DR, Smith GL, Keyes DF, Kato S, Manalo-Smith N, Wong T (2009) Toward optimal closure of the Earth's top-of-atmosphere radiation budget. J Clim 22:748-766

Michalsky JJ, Anderson GP, Barnerd J, Delamere J, Gueymard C, Kato S, Kiedron P, McComiskey A, Ricchiazzi P (2006) Shortwave radiative closure studies for clear skies during the atmospheric radiation measurement 2003 aerosol intensive observation period. J Geophys Res 111, D14S90, doi: 10.1029/2005JD006341

Minnis P, Sun-Mack S, Trepte QZ, Chang F-L, Heck PW et al (2010) CERES Edition 3 cloud retrievals. AMS 13th conference atmospheric radiation. Portland, OR, June 27-July 2, 5.4

Moody EG, King MD, Platnick S, Schaaf CB, Gao Feng (2005) Spatially complete global surface albedos: value-added datasets derived from Terra MODIS land products. IEEE Trans Geosci Remote Sens 43:144-158

Minnis P et al (2011) CERES Edition-2 cloud property retrievals using TRMM VIRS and terra and aqua MODIS data. Part I: Algorithms. IEEE Trans Geosci Remote Sens 49, 11, doi:10.1109/TGRS.2011. 2144601 (in press)

Niu X, Pinker RT, Cronin MF (2010) Radiative fluxes at high latitude. Geophys Res Lett 37:L20811. doi: 10.1029/2010GL044606

Ohmura A, Dutton EG, Forgan B, Frohlich C, Gilgen H, Hegne H, Heimo A, Konig-Langlo G, McArthur B, Muller G, Philipona R, Pinker R, Whitlock CH, Dehne K, Wild M (1998) Baseline surface radiation network (BSRN/WCRP): new precision radiometery for climate change research. Bull Amer Meteor Soc 79(10):2115-2136

Pinker RT, Laszlo I (1992) Modeling surface solar irradiance for satellite applications on global scale. J Appl Meteorol 31:194-211

Remer LA, Kaufman YJ, Tanré D, Mattoo S, Chu DM et al (2005) The MODIS aerosol algorithm, products, and validation. J Atmos Sci 62:947-973

Rienecker MM et al (2008) The GOES-5 data assimilation system-documentation of versions 5.0.1, 5.1.0, and 5.2.0. In: Suarez M (ed) NASA technical report series on global modeling and data assimilation, vol 27. NASA/TM-2008-105606

Rose F, Charlock T, Fu Q, Kato S, Rutan D, Jin Z (2006) CERES proto-edition 3 radiative transfer: tests and radiative closure over surface validation sites. In: Proceedings of 12th conference on atmospheric radiation (AMS), 10-14 July 2006, Madison, Wisconsin. Available at http://snowdog.larc.nasa.gov/ cave/

Rose FG, Charlock TP, Rutan DA, Smith GL (1997) Tests of a constrainment algorithm for the surface and atmospheric radiation budget. Extended Abstract, 9th Conference of Atmospheric Radiation, Long Beach, CA, Feb 2-7 
Rossow WB, Zhang Y-C (1995) Calculation of surface and top of atmosphere radiative fluxes from physical quantities based on ISCCP data set 2. Validation and first results. J Geophys Res 100(D1):1167-1197

Rutan D, Rose F, Roman M, Manalo-smith N, Schaaf C, Charlock T (2009) Development and assessment of broadband surface albedo from clouds and the earth's radiant energy system clouds and radiation swath data product. J Geophys Res 114:D08125. doi:10.1029/2008JD010669

Stephens GL, Wild M, Stackhouse P Jr, Ecuyer TL', Kato S (2011) The global character of the flux of downward longwave radiation. Submitted to J Clim

Su H, Wood EF, Wang H, Pinker RT (2008) Spatial and temporal scaling behaviour of surface shortwave downward radiation based on MODIS and in situ measurements. IEEE Geosci Remote Sens Let 5:542-546

Stephens GL et al (2008) CloudSat mission: performance and early science after the 1 year of operation. J Geophys Res 113, D00A18, doi:10.1029/2008JD009982

Taylor BN, Kuyatt CE (1994) Guidelines for evaluating and expressing the uncertainty of NIST measurement results, National Institute of Standard and Technology technical note 1297

Trenberth KE, Fasullo JT, Kiehl J (2009) Earth's global energy budget. Bull Amer Meteor Soc. doi: 10.1175/2008BAMS2634.1

Wang H, Pinker RT (2009) Shortwave radiative fluxes from MODIS: model development and implementation. J Geophys Res 114:D20201. doi:10.1029/2008JD010442

Wang J, Rossow WB, Zhang Y (2000) Cloud vertical structure and its variations from 20-year global rawinsonde dataset. J Clim 13:3041-3056

Wielicki BA, Cess RD, King MD, Randall DA, Harrison EF (1995) Mission to planet earth: role of clouds and radiation in climate. Bull Am Meteor Soc 76:2125-2153

Wild M, Ohmura A, Gilgen H, Morcrette J-J, Slingo A (2001) Evaluation of downward longwave radiation in general circulation models. J Clim 14:3227-3239

Winker DM, Pelon J, Coakley JA Jr, Ackerman SA, Charlson RJ, Colarco PR, Flamant P, Fu Q, Hoff R, Kittaka C, Kubar TL, LeTreut H, McCormick MP, Megie G, Poole L, Powell K, Trepte C, Vaughan MA, Wielicki BA (2010) The CALIPSO mission: a global 3D view of aerosols and clouds. Bull Am Meteorol Soc 91:1211-1229. doi:10.1175/2010BAMS3009.1

Wong T, Wielicki BA, Lee RB III, Smith GL, Bush KA, Willis JK (2006) Reexamination of the observed decadal variability of the earth radiation budget using altitude-corrected ERBE/ERBS nonscanner WFOV data. J Clim 19:4028-4040

Young DF, Minnis P, Doelling DR, Gibson GG, Wong T (1998) Temporal interpolation methods for the clouds and the earth's radiant energy system (CERES) experiment. J Appl Meteor 37:572-590

Zhang Y-C, Rossow WB, Lacis AA (1995) Calculation of surface and top of atmosphere radiative fluxes from physical quantities based on ISCCP data sets 1 . Method and sensitivity to input data uncertainties. J Geophys Res 100:1149-1165

Zhang Y-C, Rossow WB, Lacis AA, Oinas V, Mishchenko MI (2004) Calculation of radiative fluxes from the surface to top of atmosphere based on ISCCP and other global data sets: refinements of the radiative transfer model and the input data. J Geophys Res 109:D19105. doi:10.1029/2003JD004457

Zhang Y-C, Rossow WB, Stackhouse PW Jr (2006) Comparison of different global information sources used in surface radiative flux calculation: radiative properties of the surface. J Geophys Res 112: D01102. doi:10.1029/2005JD007008 